\title{
The Impact of Learning Self-efficacy on Social Support towards Learned Helplessness in China
}

\author{
Shaowei Wu ${ }^{1,2}$, Chia-Ching Tu ${ }^{3 *}$ \\ ${ }^{1}$ Doctoral Candidate in Education Management at China-ASEAN International College, Dhurakij Pundit University, THAILAND \\ ${ }^{2}$ Zhengzhou Institute of Industrial Application Technology, Zhengzhou, CHINA \\ ${ }^{3}$ Educational Management Department, CHINA-ASEAN International College, Dhurakij Pundit University, THAILAND
}

Received 11 August 2019 - Revised 23 October 2019 - Accepted 30 November 2019

\begin{abstract}
This study explored the moderating role of social support between learning selfefficacy and learned helplessness in higher vocational students in Henan Province, People's Republic of China. The Learning Self-Efficacy Scale, Social Support Scale, and Learned Helplessness Scale were adopted to conduct questionnaire surveys, which involved 1,067 students in five Chinese higher vocational colleges. A hierarchical regression model was used to analyze the role of social support in moderating the relationship between learning self-efficacy and learned helplessness. This study observed that learning self-efficacy had a negative effect on learned helplessness and that social support played a moderating role between learning self-efficacy and learned helplessness in the students.
\end{abstract}

Keywords: learning self-efficacy, learned helplessness, social support, higher vocational student, moderating role

\section{INTRODUCTION}

Learned helplessness has long troubled education systems and is an increasingly prominent and real problem in higher vocational education in the People's Republic of China (hereinafter referred to as China) along with constant expansion of higher vocational education, increasing numbers of students, and profound changes in the enrollment quality and structure of higher vocational students in recent years (Zhou, 2016). Students' learned helplessness in higher vocational education is an increasing concern for society and educators (Cui, 2013; Maslach \& Jackson, 2013; Zheng, 2013). Real-life observations and surveys have indicated that higher vocational students in China are a typical group of people with learned helplessness (Qian \& Wang, 2015). The mentality of learned helplessness may eventually cause severe negative consequences for individuals. Hen and Goroshit (2014) observed that severe learned helplessness produces self-abandonment in students. Psychological discomfort derived from learned helplessness causes adolescent college students to feel confused, spiritually empty, and pessimistic, and they eventually form incorrect outlooks on life and values (Jiang \& Yang, 2019). This phenomenon may adversely affect talent cultivation in Chinese higher vocational education (Zhou, 2016). Therefore, according to the aforementioned background and the consequences of learned helplessness, considerable attention should be paid to learned helplessness within Chinese education.

As a province with a large population, Henan Province is actively promoted as a part of the Central Plains Economic Zone as a demonstration for independent innovation (Yang, 2019). Vocational education for strategic goals is the type of education most closely related to social and economic development. Actively exploring the integration of production and education and developing vocational education have become realistic needs for promoting the coordinated development of regional economies (Wang, 2019). Higher vocational education is a crucial part of higher education in Henan Province as a new growth point for higher education and a new driving force for social and economic development in Henan Province. The rapid development of higher vocational education in Henan Province has prompted its scale to expand rapidly and the training quality of talent to be

(C) 2019 by the authors; licensee Modestum Ltd., UK. This article is an open access article distributed under the terms and conditions of the Creative Commons Attribution License (http://creativecommons.org/licenses/by/4.0/). \w0529@163.com \ chia-ching.tu@dpu.ac.th (*Correspondence) 


\section{Contribution of this paper to the literature}

- The Relationship between Vocational College Students' Self-efficacy and Learning Helplessness.

- The Self-efficacy is the cognition or traits of vocational students' interaction, which includes the support and encouragement of those around them.

- Increasing the support of family, teachers and classmates in higher vocational students can improve the emotions, helpless behavior and helpless learning.

increasingly valued by society ( $\mathrm{Su}$, Zhang, \& Cai, 2019). Therefore, higher vocational students were selected in Henan Province were selected as the study participants.

Research regarding learned helplessness is considerably rich, and most of the research participants were social adults, ordinary college students, and primary and secondary school students (Jiang, 2018; Seligman, 2001; Sorrenti, Filippello, Costa, \& Buzzai, 2015; Sullivan et al., 2012; Wang, 2014). However, research on learned helplessness in higher vocational students is rare. The problem of learned helplessness in higher vocational students is currently becoming worse (Cui, 2013; Ji, 2010). Therefore, analyzing and studying the influencing factors of learned helplessness in vocational students is necessary. The reasons for the occurrence of learned helplessness in the learning process are complex and diverse, including individual internal and external factors (Weiner, 1974). By reviewing related studies on learned helplessness, we noted that many studies only focused on the effects of learning self-efficacy on learned helplessness (Daihong, 2013; Putwain \& Symes, 2014), the effect of teacher expectation on learned helplessness (Pi \& Yan, 2010), and the relationship between social support and learned helplessness (Diener \& Dweck, 1980; Peng, 2010). For studies concerning the promotion of individual mental health, social support has typically been regarded as a moderating variable (Quan \& Wang, 2008). In this study, learned helplessness was regarded as a negative psychological state in learning individuals. Therefore, this study mainly focused on discussing the effects of social support in moderating the relationship between learning self-efficacy and learned helplessness in higher vocational students in Henan Province. Empirical investigation was also used to explore the mechanism of learning self-efficacy in moderating learned helplessness in higher vocational students from Henan Province, China, to provide a basis for higher vocational colleges to conduct interventions against learned helplessness and to promote the development of physical and mental health in higher vocational students.

\section{LITERATURE REVIEW}

According to Bandura's (1986) self-efficacy theory, students' self-efficacy directly and indirectly affects adherence to learning task completion in the learning process (Fan, 2012). According to Bandura (1986), students with low self-efficacy often exhibit negative psychological states, such as depression and anxiety, thus having pessimistic views on their performance and achievements. Several studies have reported that learning self-efficacy significantly affects the elimination and reduction of negative learning mentalities (Tan \& Zhu, 2010). Therefore, as individuals learn self-efficacy, students' negative mentality of helplessness disappears during the learning process (Putwain \& Symes, 2014). The study of Du, Zhao, You, and Zhang (2012) revealed that students with high selfefficacy are more confident in their learning ability, can effectively organize their learning, and always maintain a positive learning attitude and mentality. Ji, Liu and Li (2011) proposed educational measures against learned helplessness in college students to improve individual learning self-efficacy for reducing and preventing learned helplessness. Thus, the following hypothesis (H1) was inferred in this study: Learning self-efficacy has a significantly negative effect on learned helplessness in Chinese higher vocational students.

According to Bandura's (1986) social learning theory, the factors influencing learning are considerably complex and are not entirely individual or contextual factors but are influenced by their interaction (Bandura, 1986). As an external factor in an individual's living environment, social support often interacts with the individual cognitive factor and plays a moderating role in individuals' physical and mental health development (Li, Gao, Yang \& Liu, 2017; Quan \& Wang, 2008; Russell et al., 2016). Several studies have reported that social support can moderate the effect of self-efficacy on depression (Yang \& Wang, 2017) as well as self-consistency and congruence (Li \& Nie, 2013). Depression and learned helplessness are both passive psychological emotions, and learned helplessness is the opposite of self-consistency and self-congruence in individuals (Fan, 2002). Regarding student self-efficacy, students' academic self-efficacy is influenced by previous experiences and social support (Schunk, 1995). Gu (2014) noted from two cases that family members' care for students and support for their learning could ease students' learned helplessness. Social support is a commonly used moderating variable in academic research for improving individuals' positive emotions or reducing their negative emotions. Pi and Yan (2010) discovered that when teachers provide higher learning expectations or support for students, individual learned helplessness is reduced. $\mathrm{Li}$ and $\mathrm{Li}$ (2014) concluded that social support perceived by individuals has a significantly negative influence on learned helplessness. Social support may adjust its relationship with learned helplessness. Thus, we proposed the 


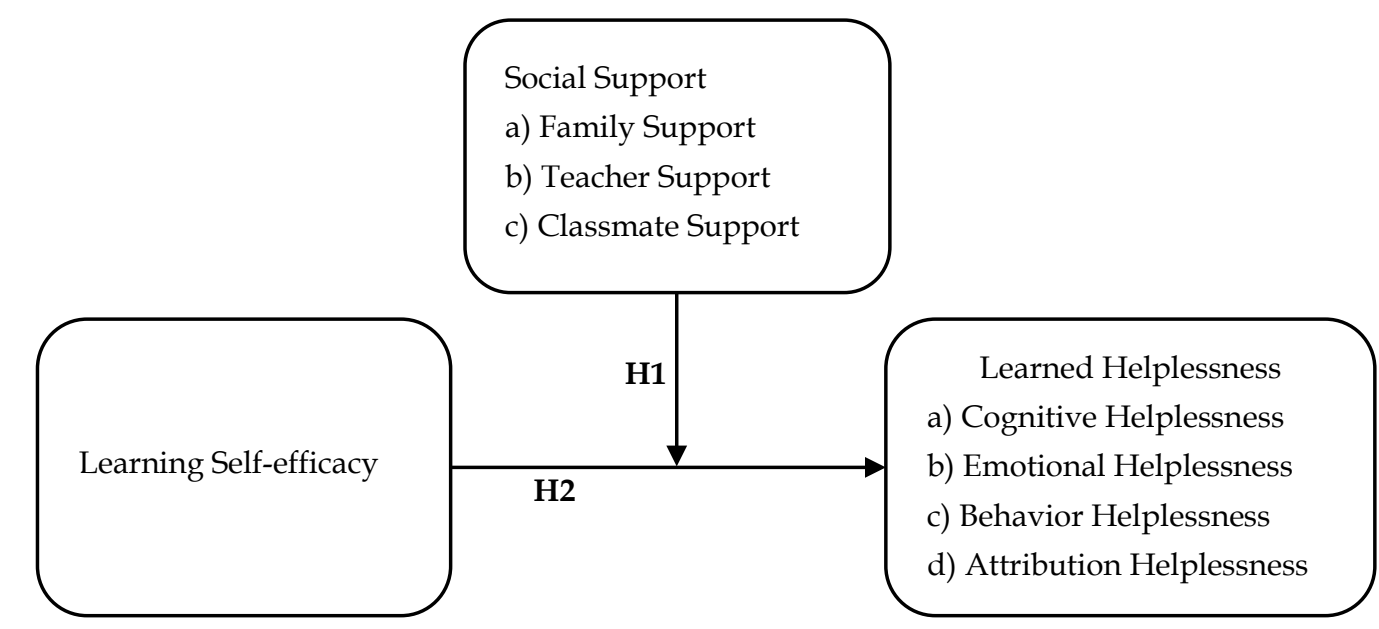

Figure 1. Theoretical Hypothesis Model Diagram

following hypothesis $(\mathrm{H} 2)$ : Social support for Chinese higher vocational students plays a moderating role on the influence of learning self-efficacy on learned helplessness.

From the aforementioned reviews of relevant theories and previous empirical studies, the following hypotheses are proposed in this study and verified through statistical analysis.

H1: Self-efficacy has a significantly negative effect on learned helplessness in Chinese higher vocational students.

H2: Chinese higher vocational students' perception of social support plays a moderating role in the influence of learning self-efficacy on learned helplessness.

\section{METHODS}

\section{Study Framework}

By combining self-efficacy theory and social learning theory, personal factors (learning self-efficacy) were used to predict the psychological state (learned helplessness) of higher vocational students in their learning process. The moderating effects of environmental factors (social support) are discussed, and a study model (Figure 1) is proposed through a literature review.

\section{Study Subjects}

According to the statistical bulletin on educational development in Henan Province, in 2018, there existed 83 higher vocational colleges in the province, the number of higher vocational students was 750,600 (Henan Provincial Department of Education, 2019). When the parent group becomes too large, random sampling becomes technically difficult for researchers. Therefore, purposive sampling (nonrandom sampling) should then be considered (Sun \& Luo, 2002). Convenient sampling is a nonrandom sampling method responding to the actual situation of researchers. This method allows for the convenient facilitation of studies to acquire the required information in time (Lin, 2002). Therefore, convenient sampling was adopted in this study, and five higher vocational colleges in Henan Province were selected as the parent group. These colleges were rated as national advanced vocational and technical education units, excellent colleges and universities in Henan Province for the evaluation of talent cultivation, and national model schools. The five colleges won awards annually in national and provincial skill competitions. Therefore, these five higher vocational colleges were selected for convenient sampling.

In this study, 1,070 higher vocational students were selected from three grades in five colleges in Henan Province through convenient sampling and provided questionnaires. Valid questionnaires were collected after all questionnaires were answered, and four invalid questionnaires were excluded. The effective recovery rate was $99 \%$. According to statistical analysis, 521 male students and 546 female students comprised the study participants, which accounted for $48.8 \%$ and $51.2 \%$ of the sample, respectively. With regard to the grade level, a total of 293 $(27.5 \%)$ were freshmen, 438 (41\%) were sophomores, and $336(31.5 \%)$ were juniors. With regard to the background of the students, $876(82.1 \%)$ students were from rural areas and $191(17.9 \%)$ were from urban areas. A total of 442 $(41.4 \%)$ students studied liberal arts, and 625 (58.6\%) studied science. Furthermore, $135(12.7 \%)$ students were only children and $932(87.3 \%)$ had siblings. These data revealed that the ratio of male to female students was relatively 
Table 1. Verification analysis and reliability analysis of the overall questionnaires

\begin{tabular}{clllll}
\hline Study Tools & Dimension & Factor load & CR & AVE & Cronbach's $\boldsymbol{\alpha}$ \\
\hline \multirow{2}{*}{ GSES } & Learning Self-efficacy & $0.64-0.80$ & 0.92 & 0.53 & 0.92 \\
\hline \multirow{3}{*}{ PSSS } & Family Support & $0.78-0.84$ & 0.88 & 0.66 & 0.88 \\
\cline { 2 - 6 } & Teacher Support & $0.78-0.85$ & 0.89 & 0.67 & 0.89 \\
\cline { 2 - 6 } & Classmate Support & $0.83-0.87$ & 0.91 & 0.72 & 0.91 \\
\hline \multirow{3}{*}{ LHS } & Cognitive Helplessness & $0.64-0.85$ & 0.87 & 0.63 & 0.87 \\
\cline { 2 - 6 } & Emotional Helplessness & $0.77-0.83$ & 0.88 & 0.65 & 0.88 \\
\cline { 2 - 6 } & Behavioral Helplessness & $0.81-0.86$ & 0.82 & 0.70 & 0.82 \\
\cline { 2 - 6 } & Attribution Helplessness & $0.82-0.86$ & 0.88 & 0.72 & 0.88 \\
\hline
\end{tabular}

Note 1: The above factors are all significant ${ }^{* \star *} p<0.001$

Note 2: CR is the composite reliability; AVE is the average variance extracted

equal in the study sample. The sample included more sophomores than juniors and freshmen; the numbers of freshmen and juniors were balanced; students from rural areas were the majority; more students studied science than liberal arts; and most students had siblings. A normality test was performed on all data to test whether the samples conformed to normal distribution. The test results indicated that the absolute value of the skewness coefficient was less than the standard value of 3 and that the absolute value of the kurtosis coefficient was less than the standard value of 10 (Kline, 1998). These results suggested that the sample data conformed to normal distribution. For statistical analysis, SPSS software was adopted to perform reliability analysis and hierarchical regression analysis on the data in this study. Moreover, AMOS software was used to analyze the data validity.

\section{Study Tools}

The Learning Self-Efficacy Scale, Perceived Social Support Scale (PSSS), and Learned Helplessness Scale (LHS) were selected as the study tools for the questionnaires.

First, the General Self-Efficacy Scale compiled by Schwarzer, Mueller, and Greenglass (1999) was used to measure the self-assessment and self-efficacy in higher vocational students for learning task completion. This scale is a single-dimension scale with 10 questions. Second, the PSSS compiled by Zimet, Dahlem, and Farley (1988) was used for determining minor changes in this study according to the actual status of higher vocational students. In the PSSS, "family, friends, others" was changed to "family, teachers, classmates." This scale contains 12 questions, including questions concerning the dimensions of family, teacher, and classmate support. Finally, the LHS developed by Quinless and Nelson (1988) was used to measure learned helplessness in higher vocational students. This scale contains 20 questions on four dimensions: cognitive helplessness (helplessness in personal cognition), emotional helplessness (helplessness in personal emotions), behavioral helplessness (helplessness when facing learning tasks), and attribution helplessness (attribution of helplessness to negative events).

Confirmatory factor analysis was used to test the validity of the three scales of learning self-efficacy, social support, and learned helplessness in this study. First, by testing the fit indices of the three scales, the root mean square residual was within 0.02-0.04, normed fit index was within 0.92-0.97, confirmatory factor analysis was within $0.92-0.98$, relative fit index was within $0.90-0.97$, and parsimonious normed fit index was within $0.71-0.73$. Therefore, the fit indices of the three scale models were all standard. In addition, the results in Table 1 indicated that the load of all questions in the three scales was greater than 0.5 , the composite reliability was within $0.88-0.92$, and the average variation was within $0.53-0.72$. Cronbach's a was used to detect the reliability of the three scales. The results revealed that the Cronbach's a coefficient in each dimension of the scales was within 0.82-0.92. The results also indicated that the scales had good reliability and validity (Lomax \& Schumacker, 2004; Nunnaglly, 1978). The details are listed in Table 1.

\section{Deviation Test of the Same Method}

Self-reporting was adopted to collect data, and thus, deviations of the same method may have occurred. Therefore, on the basis of previous studies, preprocedural control and postmortem statistical tests were used to prevent deviations of the same method. First, during the questionnaires, strict procedural control was adopted, the participants were notified that the questionnaire results were only for academic research, and information was entirely confidential and anonymous. In the post hoc detection, the Harman single factor test was adopted in data analysis, and all test items of variables were added into the same survey project for analysis. After testing, five principal components were extracted before factor rotation. The first factor suggested that the variation was $28.12 \%$, which was less than the critical standard (40\%) (Podsakoff, MacKenzie, \& Podsakoff, 2003). Therefore, no deviation of the same method occurred in this study. 
Table 2. Correlation Matrix Analysis

\begin{tabular}{llll}
\hline Variable & LS & LH & SS \\
\hline Learning Self-efficacy (LS) & 1 & & \\
\hline Learned Helplessness (LH) & $-.18^{* \star *}$ & 1 & \\
\hline Social Support (SS) & $.44^{* \star *}$ & $-.23^{* \star *}$ & 1 \\
\hline Note* ${ }^{* \star} p<0.001$ & & &
\end{tabular}

Note: ${ }^{* * *} p<0.001$

Table 3. The Moderating Validity Table of Social Support between Learning Self-efficacy and Learned Helplessness

\begin{tabular}{|c|c|c|c|c|}
\hline \multirow{2}{*}{ Item } & Model 1 & Model 2 & Model 3 & \\
\hline & \multicolumn{3}{|c|}{ Learned Helplessness (Dependent Variable) } & VIF \\
\hline (Control Variable) & Beta & Beta & Beta & \\
\hline Male & $.07^{*}$ & .05 & $.07^{*}$ & 1.03 \\
\hline First Grade & $-.12^{* \star \star}$ & $-.11^{* *}$ & $-.10^{* *}$ & 1.37 \\
\hline Second Grade & -.05 & -.05 & -.05 & 1.36 \\
\hline \multicolumn{5}{|l|}{ (Independent Variable) } \\
\hline Learning Self-efficacy & $-.18^{* \star \star}$ & $-.11^{\star \star \star}$ & $-.13^{\star \star \star}$ & 1.25 \\
\hline \multicolumn{5}{|l|}{ (Moderator Variable) } \\
\hline Social Support & - & $-.16^{* * \star}$ & $-.18^{* * \star}$ & 1.26 \\
\hline \multicolumn{5}{|l|}{ (Interaction Variable) } \\
\hline Learning Self-efficacy $x$ Social Support & & & $-.22^{* * *}$ & 1.03 \\
\hline $\mathrm{R}^{2}$ & .05 & .07 & .11 & \\
\hline $\operatorname{adj} R^{2}$ & .04 & .06 & .11 & \\
\hline$\triangle R^{2}$ & - & - & .04 & \\
\hline$F$ & $14.22^{* * *}$ & $16.65^{* * *}$ & $23.85^{\star \star \star}$ & \\
\hline
\end{tabular}

Note $1:{ }^{*} p<0.05 ;{ }^{* *} p<0.01 ;{ }^{* * *} p<0.001$

Note 2: Female and grade 3 students were set as the control group

\section{RESULTS}

\section{Moderating Role of Social Support}

According to the literature review, social support was set as the moderator variable, learning self-efficacy was set as the independent variable, and learned helplessness was set as the dependent variable in this study to establish a regression model. Hierarchical regression analysis was adopted to examine the role of social support in moderating learning self-efficacy and learned helplessness for higher vocational students. In addition, before verifying the moderating effects, Pearson correlation analysis was adopted to examine the correlations among the study variables, as presented in Table 2 .

According to James and Brett (1984) and Baron and Kenny (1986), the following three steps were adopted to verify moderating effects:

1. The independent variable must achieve a significant regression coefficient for the dependent variable.

2. The independent and moderator variables are simultaneously added to the regression model to achieve a significant regression coefficient.

3. The independent, moderator, and interaction variables of the dependent and moderator variables are added to the regression model, and the interaction variable of the dependent and moderator variables can achieve significant regression coefficients. The moderator variable is then judged to have a moderating effect.

To prevent the correlation between the predictor and interaction variables from being too high and thus leading to collinearity, we converted the values of the independent and moderator variables into $\mathrm{Z}$ scores according to the study by Aiken, West, and Reno (1991). We then calculated the multiplication product and used the variance expansion factor (VIF) as a collinearity test indicator. VIF values greater than 10 indicated significant collinearity between the variables (Myers, 1990).

Levels of social support and learned helplessness significantly differed among higher vocational students between genders and grade levels in this study. Thus, background variables (gender and grade) were used as control variables in the regression model. The analysis results obtained with the hierarchical regression test are listed in Table 3 . When controlling the gender and grade background variables, the learning self-efficacy independent variable can explain 5.1\% of the learned helplessness in Model $1(F=14.22, p=0.000)$. After the social support moderator variable was added, it could explain $7.3 \%$ of the learned helplessness in Model $2(F=16.65, p=$ 0.000). In Model 3, after inputting the interaction variable, the explanation could be increased by $4.6 \%$ and the overall explanation could reach $11.9 \%(F=23.85, p=0.000)$. In the hierarchical regression model (Model 3), the VIF 


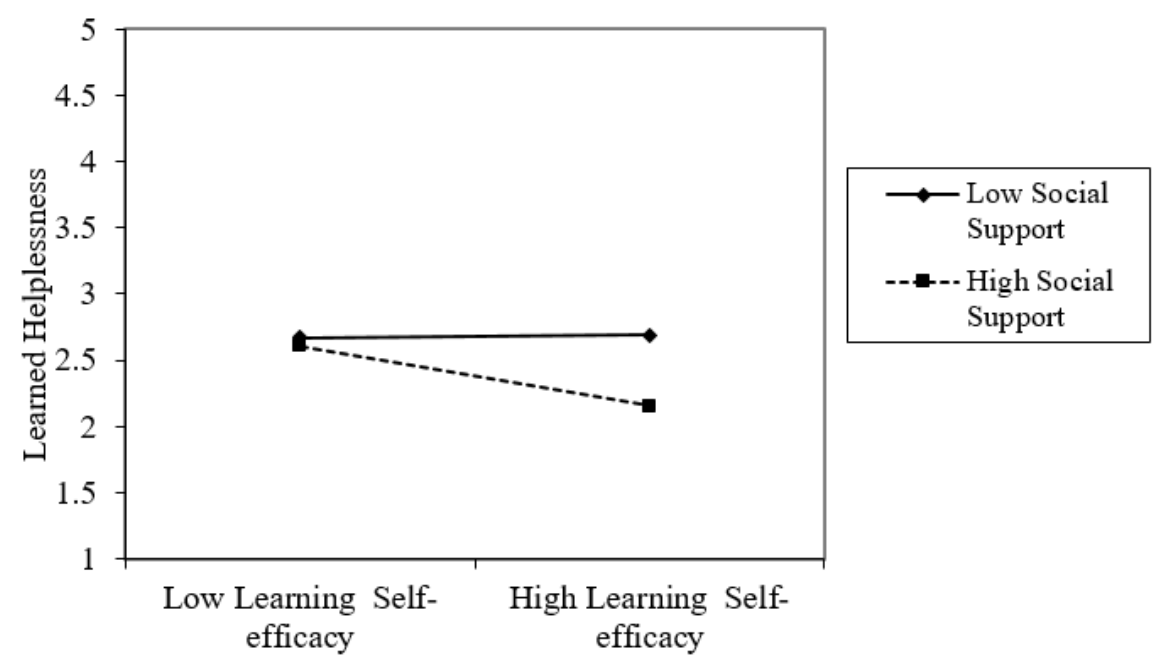

Figure 2. The Moderating Effect Diagram of Social Support

was within 1.034-1.375. All VIF were less than 10, which indicated that the learning self-efficacy, social support, and interaction variables of learning self-efficacy and social support were not collinear with each other, as presented in Table 3.

The results in Table 3 indicated that in Model 3, learning self-efficacy negatively predicted learned helplessness $(\beta=-0.13, p=0.000)$, social support significantly and negatively predicted learned helplessness $(\beta=-0.18, p=$ $0.000)$, and the interaction variable of learning self-efficacy and social support significantly and negatively predicted learned helplessness $(\beta=-0.22, p=0.000)$, which indicated that the effect of learning self-efficacy on learned helplessness was moderated by social support.

The interaction figure was analyzed to understand the role of social support in moderating learning self-efficacy and learned helplessness. Simple slope regression analysis was also adopted in this study (Chao, Wei, Good \& Flores, 2011). The results in Figure 2 revealed that students with low self-efficacy were more likely to experience learned helplessness than were those with high self-efficacy regardless of the level of social support. Du et al. (2012) noted that students with high self-efficacy have more confidence in their learning, can effectively organize their learning, and always maintain a positive learning attitude and mentality, which is consistent with Putwain and Symes' study (2014), according to which the negative mentality of students with helplessness disappears as learning self-efficacy increases. The study also discovered that social support perceived by higher vocational students plays a positive role in influencing learning self-efficacy on learned helplessness. Therefore, students who perceive high levels of social support better inhibit learned helplessness than do students who perceive low levels of social support. As the learning self-efficacy level increases, the students who perceive high levels of social support are more likely to suppress learned helplessness than are students who perceive low levels of social support. This study also found that students with high learning self-efficacy are more likely to have less learned helplessness when perceiving higher social support levels. This finding is consistent with Bandura's (1986) social learning theory. The factors affecting learning activities are susceptible to interactions between individual and contextual factors. Russell (2016) stated that social support, as an external factor in individuals' living environment, often interacts with the personal cognitive factors of individuals (such as learning self-efficacy) to moderate their physical and mental health.

In summary, the relationship between the variables and the moderating effect was verified through hierarchical regression analysis and both $\mathrm{H} 1$ as well as $\mathrm{H} 2$ were verified.

\section{CONCLUSION AND SUGGESTIONS}

\section{Levels of Learning Self-Efficacy, Social Support, and Learned Helplessness in Higher Vocational Students}

From the descriptive statistical results of self-efficacy, social support, and learned helplessness in higher vocational students, the overall average level of learning self-efficacy was higher than the median value of 3, which was the upper middle level. Therefore, current higher vocational students in Henan Province had a certain degree of confidence in their learning ability and learning methods toward college studies. For the level of perceived social support, medium levels of higher vocational student learning burnout and its three dimensions (emotional 
exhaustion, cynical attitude, and sense of low achievement) were observed, which indicated that although the level of learning burnout in higher vocational students was not very high in general, learning burnout still occurred in some higher vocational students. Sense of low achievement displayed the highest average score compared with the other two dimensions, which indicated that higher vocational students lacked the motivation to learn. Even when progress is made, producing a sense of achievement is still difficult and a sense of low achievement is obvious, which is consistent with other research results (Song \& Luo, 2018). The overall learned helplessness and its four dimensions (cognitive, behavioral, emotional, and attribution helplessness) in higher vocational students were at a medium level. Although the level of learned helplessness in higher vocational students was not high in general, some higher vocational students still experienced learned helplessness, where students had higher scores for cognitive and behavioral helplessness than for the other two dimensions. This result indicated that several higher vocational students had a bias against learning and cognition, lacked confidence in their learning ability and endurance, and lost the courage and confidence to continue to try. For example, in the learning process, higher vocational students considered that their intelligence was not sufficiently high and hence their academic performance would be poor no matter how hard they tried. Thus, they negatively believed that improving and promoting their learning was difficult (Qian \& Wang, 2015).

\section{Predictive Effect of Learning Self-Efficacy on Learned Helplessness in Higher Vocational Students}

Learning self-efficacy had a negative impact on learned helplessness for higher vocational students. Thus, higher learning self-efficacy in higher vocational students resulted in lower levels of learned helplessness. Students with low self-efficacy were often skeptical regarding their ability to complete learning tasks. Before performing a learning task, they did not strive for success but fixed their attention on possible failures in the task. When encountering setbacks, they often did not have self-confidence and they directly gave up without any intention to work hard. The helpless mentality that gradually forms in learning is called learned helplessness. Students with high self-efficacy have more confidence in learning, have more motivation to learn, and thus can ultimately avoid the negative learning mentality of learned helplessness. Du et al. (2012) discovered that students with high selfefficacy have more confidence in learning behaviors, can effectively organize their learning, and always maintain a positive learning attitude and mentality, thus avoiding negative learning attitudes or mentalities such as learned helplessness. This conclusion is consistent with other researchers' views (Putwain \& Symes, 2014).

\section{Moderating Role of Social Support in the Relationship between Self-Efficacy and Learned Helplessness}

Through statistical analysis, this study revealed that social support played a moderating role in the relationship between learning self-efficacy and learned helplessness in higher vocational students and that students with high levels of social support were more likely to inhibit learned helplessness than were students with low levels of social support. As the learning self-efficacy level increased, students with high levels of social support more effectively inhibited learned helplessness than did students with low levels of social support because higher vocational students with high levels of learning self-efficacy had more optimistic evaluations on their learning ability and more confidence in learning. When family members, teachers, or classmates give them sufficient attention and support, higher vocational students have more enthusiasm and willingness to participate in learning activities and thus achieve more success. Even when encountering failure, they are still willing to continue learning and dealing with difficult learning tasks with self-confidence and social support, thus avoiding learned helplessness. In addition, according to Bandura's discussion on interaction $(1977,1986)$ in social learning theory, psychological function is a process in which the three dimensions of environment, individuals, and behavior continuously interact with each other and the environment in which the individual is located interacts with individual cognition to affect psychological behavior. Therefore, self-efficacy is the cognition or trait of higher vocational students to interact with their environment, which mostly includes the support and encouragement of the people around them. Thus, the self-confidence of higher vocational students is constantly enhanced and a positive psychological state is established, which ultimately affects the learned helplessness of higher vocational students. Social support, as an external environmental factor, regulates the influence of learning self-efficacy on learned helplessness. Therefore, the results of this study echoed Bandura's $(1977,1986)$ discussion on interactions in social learning theory.

In summary, the results of this study are crucial in enriching social learning theory and provide guiding significance for the work of education administrators. Support and care from family members, teachers, and classmates is a key aspect of social support for higher vocational students. Support from other important people can stimulate more active learning behavior during learning and growth in higher vocational students. For educational management activities, in addition to cultivating learning self-efficacy in higher vocational students, 
support from family members, teachers, and classmates can also be increased to improve positive emotions and behavior toward learning and to prevent learned helplessness in higher vocational students.

\section{Suggestions}

This study provides the following suggestions to educational administrators of higher vocational students, such as family members and school educators:

For family members, parents can strengthen communication with their children in daily life and pay attention to their daily study and school lives, improve parental care for higher vocational students, and allow them to perceive more concern. When higher vocational students encounter difficulties in learning activities, parents may encourage and praise them and provide them with support to promote self-confidence development and prevent learned helplessness (Peng, 2010). Furthermore, strengthening contact with counselors of higher vocational students is necessary because they can always pay attention to student performance in school. Counseling may help higher vocational students to more effectively moderate their behavior and moods, improve their ability to adapt to environmental changes, and prevent the development of learned helplessness.

For school education and educational administrators, teachers can teach students content regarding happiness and encourage students to be optimistic in facing any life problems and to approach studying during and after class with happiness, contentment, and optimism. A democratic and equal educational environment can effectively improve communication quality between teachers and students, establish good teacher-student relationships, and enable students to have complete confidence in themselves, thereby improving learning self-efficacy in higher vocational students. In the normal teaching process, learning difficulties and communication with students should be approached with considerable care. Allowing students to perceive more care and improving teachers' care for students is necessary. For example, on a student-centered basis, students should be more encouraged and praised to allow them to experience more feelings of accomplishment. Furthermore, prosocial behavioral education, such as education on etiquette, caring for others, correct world views, outlooks on life and values, and healthy personality, are also suggested. Teaching students to care for others and giving students more learning and emotional support is necessary to reduce learned helplessness in higher vocational students.

For school management, higher vocational colleges should organize more activities regarding student emotional management, arrange professional tutors to conduct emotional management courses, cultivate student understanding of the true meaning of positive emotions, and teach how to maintain positive emotions such as pleasure, contentment, and optimism. In these activities, students should learn to eliminate negative emotions and master how to actively transform themselves into people with positive, happy, contented, and optimistic emotions. With the help of teaching administrators in colleges, higher vocational students' self-efficacy can be improved (Costello \& Stone, 2012) and learned helplessness can be prevented.

This study also provides suggestions regarding research participants, content, and methods to provide a reference for future academic studies.

With regard to research participants, future research can be extended to higher vocational students in other provinces, such as Hubei, Jiangxi, and Shandong. The number of research samples should be expanded to allow for more comprehensive data collection. Moreover, comprehensive surveys can be conducted of students in additional types of higher vocational colleges and of higher vocational students before and after internships.

With regard to research content, researchers may perform examinations on factors such as personality traits of higher vocational students, relationships of higher vocational students with their parents and other important people, teachers' expectations, learning pressure and learning interest as well as the effects of these factors on learned helplessness (Jiang \& Peng, 2008) to achieve comprehensive assessments.

With regard to research methods, Creswell and Clark (2017) argued that researchers should adopt a mixed technique that combines qualitative and quantitative methods to clarify subtle differences and interactively validate research findings. Therefore, methods such as interviews, individual case studies, and vertical surveys are suggested for future research to systematically and comprehensively examine learned helplessness and its influencing factors in higher vocational students. Vertical and deep qualitative and quantitative research can supplement the insufficiency of the cross-sectional investigation and quantitative statistical analysis adopted in this study.

\section{REFERENCES}

Bandura, A. (1986). Social foundations of thought and action. NJ: Englewood Cliffs.

Bandura, A. (1993). Perceived self-efficacy in cognitive development and functioning. Educational psychologist, 28(2), 117-148. https:/ / doi.org/10.1207/s15326985ep2802_3 
Costello, C. A., \& Stone, L. M. (2012). Positive psychology and self-efficacy: potential benefits for college students with attention deficit hyperactivity disorder and learning disabilities. Journal of Postsecondary Education $\mathcal{E}$ Disability, 25, 119-129.

Creswell, J. W., \& Clark, V. L. P. (2017). Designing and conducting mixed methods research. London: Sage publications.

Cui, J. G. (2013). Interpreting the phenomenon of "learned helplessness" in vocational students: psychological crux and educational strategies. Chinese Vocational and Technical Education, 2, 21-20.

Du, J. J., Zhao, Z. Y., You, Y. Z., \& Zhang, S. X. (2012). Case study on the learning motivation and learning strategies in vocational students with higher learning achievement. Nantai Journal of Humanities and Social Sciences, (7), 25-52.

Fan, F. M. (2002). Study on mental health education of college students. Beijing: Tsinghua University Press Co. LTD.

Fan, X. H. (2012). Improving self-efficacy and stimulating learning potential. Modern Reading (Education Edition), (17), 447.

$\mathrm{Gu}$, L. L. (2014). To analyze the influence of bad parent-child relationship on higher vocational group with learned helpless - thoughts based on two cases. Journal of Xingtai Polytechnic College, (6), 56-59.

Hen, M., \& Goroshit, M. (2014). Academic procrastination, emotional intelligence, academic self-efficacy, and GPA: A comparison between students with and without learning disabilities. Journal of Learning Disabilities, 47(2), 116-124. https:// doi.org/10.1177/0022219412439325

Hmieleski, K. M., \& Baron, R. A. (2008). When does entrepreneurial self-efficacy enhance versus reduce firm performance? Strategic Entrepreneurship Journal, 2(1), 57-72. https:/ / doi.org/10.1002/sej.42

James, L., \& Brett, J. (1984). Mediators, moderators, and test for mediation. Journal of Applied Psychology, 69, $307-321$. https:/ / doi.org/10.1037/0021-9010.69.2.307

Ji, W., Liu, L. L., \& Li, Y. (2011). A review of studies on learned helplessness. Journal of Jilin Institute of Education, 27(06), 98-99.

Jiang, J. G., \& Yang, P. P. (2019). Internet prayer: lucky game, spiritual smuggling and identity dilemma. Exploration and Free Views, 1(1), 68-70.

Jiang, Z. M. (2018). Survey and analysis of college students' learned helplessness in class learning. Western Quality Education, 4(02), 18-20.

Kumcagiz, H., Ersanli, E., \& Alakus, K. (2014). Hopelessness, procrastination and burnout in predicting job satisfaction: A reality among public school teachers. International Journal of Academic Research, 6(1), 333-339. https:/ / doi.org/10.7813/2075-4124.2014/6-1/B.45

Li, C. Y. (2008). Cultivating the self-efficacy of higher vocational students in the teaching of specialized courses. Reading and Writing (Teacher Education), (7), 13-15.

Li, X. J., \& Li, Z. J. (2014). Improve social support, reduce learned helplessness - research on the relationship between middle school students' social support and learned helplessness. Hebei Education (Moral Education Edition), (10), 27-30.

Li, X. Y., Gao, D. D., Yang, J., \& Liu, Y. (2017). The influence of loneliness on depression: the effect of social support on internet addiction. Phycology Research, 10(06), 78-85.

Li, Y., \& Nie, Y. G. (2013). The relationship among subjective social support, self-efficacy and self-consistency of college students. Journal of Guangzhou University (Social Science Edition), 12(09), 56-59.

Lomax, R. G., \& Schumacker, R. E. (2004). A beginner's guide to structural equation modeling. New Jersey: Lawrence Erlbaum Associates, Inc., Publishers. https:/ / doi.org/10.4324/9781410610904

Maslach, C., \& Jackson, S. E. (2013). A social psychological analysis. Social Psychology of Health and Illness, 3(9), 227230.

Nunnally, J. (1978). Psychometric methods, New York: McGraw-Hill.

Peng, F. X. (2010). The manifestation, causes and countermeasures of "cold violence" in parent-child relationship. Journal of Educational Development (Second Half), (7), 83-85.

Pi, L., \& Yan, Z. R. (2010). The influence of teacher expectation on learned helplessness in mathematics learning. Journal of Mathematics Education, 19(1), 44-47.

Podsakoff, P. M., MacKenzie, S. B., Lee, J. Y., \& Podsakoff, N. P. (2003). Common method biases in behavioral research: A critical review of the literature and recommended remedies. Journal of Applied Psychology, 88(5), 879-903. https:/ / doi.org/10.1037/0021-9010.88.5.879

Pompili, M., Innamorati, M., Narciso, V., Kotzalidis, G., Dominici, G., Talamo, A., \& Tatarelli, R. (2010). Burnout, hopelessness and suicide risk in medical doctors. La Clinica Therapeutica, 161(6), 511-514. 
Putwain, D. W., \& Symes, W. (2014). The perceived value of maths and academic self-efficacy in the appraisal of fear appeals used prior to a high-stakes test as threatening or challenging. Social Psychology of Education, 17(2), 229-248. https:/ / doi.org/10.1007/s11218-014-9249-7

Qian, Y. L., \& Wang, J. J. (2015). Investigation and cause analysis of learned helplessness in vocational students. Value Engineering, 34(6), 321-322.

Quinless, F. W., \& Nelson, M. M. (1988). Development of a measure of learned helplessness. Nursing Research. 5(3), 210-213. https:// doi.org/10.1097/00006199-198801000-00003

Russell, D. W., Benedek, D. M., Naifeh, J. A., Fullerton, C. S., Benevides, N., Ursano, R. J., \& Cacciopo, J. T. (2016). Social support and mental health outcomes among US Army Special Operations personnel. Military Psychology, 28(6), 361. https://doi.org/10.1037/mil0000114

Schunk, D. H. (1995). Self-efficacy and education and instruction. In J. E. Maddux (Ed.), Self-efficacy, adaptation, and adjustment: Theory, Research, and Application (pp. 281-303). New York: Plenum Press. https:/ / doi.org/10.1007/978-1-4419-6868-5_10

Schwarzer, R., Mueller, J., \& Greenglass, E. (1999). Assessment of perceived general self-efficacy on the Internet: Data collection in cyberspace. Anxiety, Stress and Coping, 12(2), 145-161. https:/ / doi.org/10.1080/10615809908248327

Sorrenti, L., Filippello, P., Costa, S., \& Buzzai, C. (2015). A psychometric examination of the Learned Helplessness Questionnaire in a sample of Italian school students. Psychology in the Schools, 52(9), 923-941. https://doi.org/10.1002/ pits.21867

Su, X. L., Zhang, X. J., \& Cai, T. C. (2019). Research on the development of higher vocational education in Henan Province. Journal of Jiyuan Vocational and Technical College, (1), 9-13.

Sullivan, D. R., Liu X. G., Corwin, D. S., Verceles, A. C., McCurdy, M. T., Pate, D. A., Davis, J. M., \& Netzer, G. (2012). Learned helplessness among families and surrogate decision-makers of patients admitted to medical, surgical, and trauma ICUs. Chest, 142(6), 1440-1446. https:/ / doi.org/10.1378/chest.12-0112

Sun, Y. L., \& Luo, L. H. (2002). Problem of sampling in educational research-purposive sampling. Journal of Yunnan Normal University, 34 (3), 127-128.

Tan, S. X., \& Zhu, H. (2010). Relationship between self-efficacy, coping style and anxiety in higher vocational students. China Public Health, 26(8), 961-962.

Wang, H. (2014). Study on the acquired helplessness of English major students in independent colleges. Campus English, (6), 4-5.

Wang, H. (2019). To explore the integration of production and education in Henan vocational education and the coordinated development of regional economy. Neijiang Technology, 40(03), 15-16.

Weiner, B. (1974). Achievement motivation and attribution theory. NY: General Learning Press.

Yang, X. Y. (2019). Research on the current situation and countermeasures of talent cultivation model in private colleges in Henan Province. Journal of Beijing Agricultural University, 33(1), 12-16.

Yang, Y. T., \& Wang, G. L. (2017). Moderating role of social support between children's self-efficacy and depression. Chinese Journal of Public Health, 33(06), 1008-1009.

Yu, J. H., Chae, S. J., \& Chang, K. H. (2016). The relationship among self-efficacy, perfectionism and academic burnout in medical school students. Korean Journal of Medical Education, 28(1), 49-53. https:// doi.org/10.3946/kjme.2016.9

Zheng, A. W. (2013). An exploration on the phenomenon of "learned helplessness" in the learning of higher vocational students. Vocational Education Research, 1, 42-43.

Zhou, R. (2016). A study on learned helplessness and teaching reform in higher vocational colleges. Asia-pacific Education, 16(1), 7714-7716.

\section{http://www.ejmste.com}

